\section{HUMAN FACTORS IN FARMING—PUBLISHING THE LEARNING FROM ACCIDENT REVIEWS TO INFLUENCE FARMERS' BEHAVIOURS AND PRACTICES}

doi:10.1136/injuryprev-2012-040590m.28

Polaczuk Chris, Nagel Megan, Jones Peter Hamilton. Correspondence: Accident Compensation Corporation, PO Box 242, Wellington, New Zealand

Objective To reduce injuries to farmers by sharing the learning gained from reviews of farm accidents using a human factors analysis tool.

Methods A group of farm consultants were trained in the Keil Centre's human factors analysis tool. They reviewed 23 farm accidents and prepared standard reports for entry into an Accident Compensation Corporation (ACC) database for analysis. Based on the reports 12 plain English stories were written using fictitious personal information to protect the farmers' privacy. The stories are being published in rural magazines, and used in radio interviews with farming representatives, to share the learning with the wider farming community. An independent survey was conducted to evaluate if the farmers concerned had changed their behaviours following these on-farm reviews, and to provide feedback on the usefulness of this approach.

Results The survey feedback from farmers was 95\% positive. Most farmers found the reviews useful - they made them think differently and change practices and behaviours on their farms. Database analysis enabled ACC to identify common human factors that contribute to farm accidents with high numbers of 'decision errors' becoming apparent.

Conclusions This project demonstrated that using a human factors analysis tool to review farm accidents provides useful insights, the publication of which provides an on-going means to influence farmers' behaviours and practices in the wider farming community. 